Article

\title{
Green Synthesis of ZnO Nanostructures Using Salvadora Persica Leaf Extract: Applications for Photocatalytic Degradation of Methylene Blue Dye
}

\author{
Fahad A. Alharthi ${ }^{1, *,+}$, Abdulaziz Ali Alghamdi ${ }^{1,+}{ }^{,}$Asma A. Alothman ${ }^{1}{ }^{10}$, \\ Zainab M. Almarhoon ${ }^{1}{ }^{\mathbb{D}}$, Munairah F. Alsulaiman ${ }^{1}$ and Nabil Al-Zaqri ${ }^{1,2}{ }^{(D)}$ \\ 1 Department of Chemistry, College of Science, King Saud University, P.O. Box 2445, Riyadh 11451, \\ Saudi Arabia; aalghamdia@ksu.edu.sa (A.A.A.); aaalothman@ksu.edu.sa (A.A.A.); \\ zalmarhoon@ksu.edu.sa (Z.M.A.); munairah.f.s@hotmail.com (M.F.A.); nalzaqri@ksu.edu.sa (N.A.-Z.) \\ 2 Department of Chemistry, College of Science, Ibb University, P.O. Box 70270, Ibb, Yemen \\ * Correspondence: fharthi@ksu.edu.sa \\ + These authors contributed equally to this work.
}

Received: 23 April 2020; Accepted: 28 May 2020; Published: 30 May 2020

\begin{abstract}
Various $\mathrm{ZnO}$ nanomaterials such as nanorods, nanoparticles, and nanosheets were synthesized using Salvadora persica leaf extract via the sol-gel method. The prepared nanomaterials possess a large number of nanocavities. The synthesized nanomaterials were characterized using X-ray diffraction (XRD), Fourier-transform infrared spectroscopy (FT-IR), UV-visible diffuse reflectance studies (UV-DRS), scanning electron microscopy (SEM), and high resolution transmission electron microscopy (HT-TEM), and these nanomaterials were used to test photocatalytic applications for the degradation of highly hazardous methylene blue dye. The degradation efficiency was higher for materials with nanorods and nanosheets with nanocavities; this was due to the presence of the nanocavities, which made the catalyst more sensitive to light absorption. This method offers a green synthesis of different nanomaterials in bulk quantity at low cost.
\end{abstract}

Keywords: green synthesis; sol-gel method; nanorods; nanosheets; nanoparticles; photocatalytic

\section{Introduction}

Dye impurities in effluents from printing, textiles, and production industries play an adverse role in polluting the environment. This waste enters the aquatic ecosystem and causes environmental and health risks to the aquatic life, which, in turn, eventually affect human life. Techniques such as coagulation, adsorption, osmotic pressure, etc., have been used to remove dyes from rivers and other water bodies, but each method has unique advantages and limitations [1]. Among the various techniques employed, photocatalytic treatment for the removal of dye provides a relatively inexpensive and eco-friendly way to solve this problem [2].

Zinc oxide nanoparticles ( $\mathrm{ZnO} N \mathrm{NP}$ ) are the essential nanoparticles that are employed in various areas of daily life due to their distinctive chemical and physical properties. They have been utilized extensively as additives in the rubber industry, textile industry, biomedical imaging, antimicrobial agents, and cosmetic products [3-7]. In the area of catalysis, apart from their various applications, including as oxidation catalysts for the conversion of alkanes, the functionalization of benzene, the fabrication of heavily functionalized $4 \mathrm{H}$-chromenes and the $\mathrm{N}$-formylation of amines [8,9], they have been extensively used as photocatalysts due to their high binding energy $(60 \mathrm{meV})$ with a well-known n-type wide-bandgap metal oxide semiconductor $(3.37 \mathrm{eV})[10,11]$ for the degradation of many organic pollutants [12]. Other reasons for the increased use of the ZnO NPs as photodegradation catalysts 
is their low cost and characteristics as the hardest material, which induce their ability to overcome physical endurance [13].

Therefore, $\mathrm{ZnO}$, is the one material that can address the issue of the degradation of dye in our water system. However, the two main issues usually faced in the attempts to synthesize $\mathrm{ZnO}$ nanostructures are (i) a lack of synthesis techniques that are fast, economical, and environmentally benign and (ii) a difficulty in producing stable p-type doping. Keeping this in mind, a plethora of methods for the synthesis of $\mathrm{ZnO}$ nanocrystals has been carried out extensively using a variety of methods such as the solvothermal, hydrothermal, direct precipitation, and sol-gel methods [14-17]. However, most of these approaches require sophisticated equipment, long reaction times, difficult experimental environments, and expensive substrates.

Moreover, apart from the abovementioned protocols, the sonochemcial approach, an alternative green protocol, has been developed by Vabbina et al. for the synthesis of 1D ZnO Nanorods, core-shell nanorods, 2D nanowalls and nanoflakes on arbitrary substrates, which is a rapid, inexpensive, CMOS-compatible and environmentally benign method; however, this method cannot be implemented easily, as it requires a sonicator water bath [18-20]. Moreover, the other hand, other alternative routes for the synthesis of nanoparticles without the requirement of sophisticated equipment have been studied and reported extensively as green synthesis protocols [21-23] and can be easily extended to the synthesis of nanocomposites [24-27]. Among the various nanoparticles, green synthesis of $\mathrm{ZnO}$ has also been studied using various plant extracts such as Cordia myxa, Trifolium pratense flower extract, Tecoma castanifolia leaf extract, Limonia acidissima, Echinacea, Aristolochia indica, Mentha, Boswellia ovalifoliolata, etc. [28-36].

S. persica is an evergreen, deep-basin, hairless tree or small shrub. The branches are sagging, and the leaves are thin, oval, ovate, and mucoid. A phytochemical evaluation of S. persica leaf extract revealed that it mainly consists of aniline (28.65\%), 2,6-dimethyl- $N$-(2-methyl- $\alpha$-phenylbenzyl), homo- $\gamma$-linolenic acid (12.63\%), methyl hexadecanoate (11.01\%), and spiculesporic acid $(13.60 \%)$, there structures are show in Scheme 1. These components act as bioagents for biological activity against potato soft and brown-rot bacteria [37], and the extract is widely used for its medicinal properties, such as antibacterial activity, and as a natural toothbrush. However, to the best of our knowledge, this plant extract has not yet been employed for the synthesis of nanoparticles.

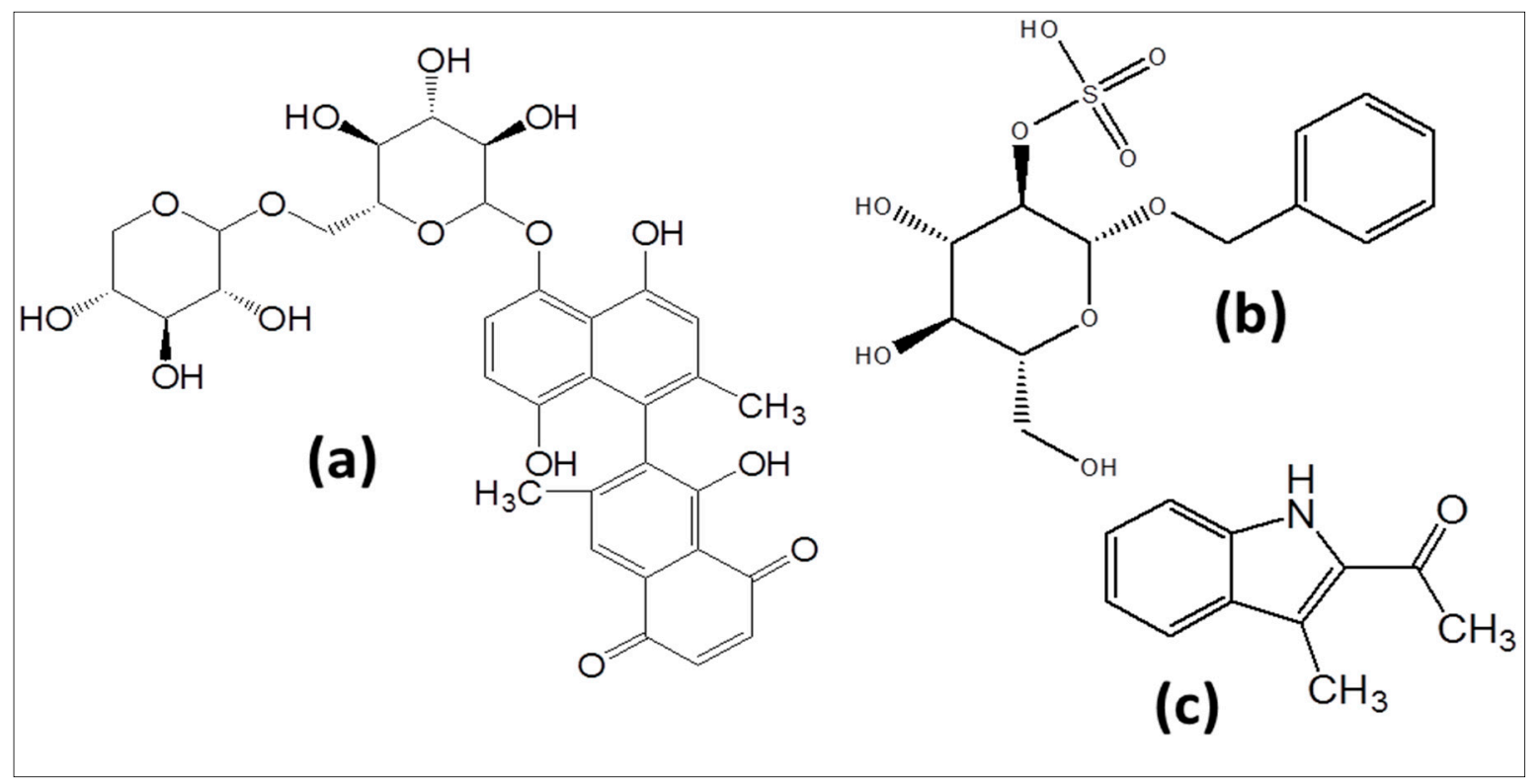

Scheme 1. Structure of (a) salvadorine, (b) salvadoside, and (c) salvadoricine. 
Therefore, in this study, for the first time, a novel method of sol-gel green synthesis using S. persica leaf extract was employed as a green surfactant/capping agent for the green synthesis of $\mathrm{ZnO}$ nanoparticles. The obtained nanoparticles were characterized using powder $\mathrm{X}$-ray diffraction, Fourier-transform infrared spectroscopy, UV-visible spectrum, scanning electron microscopy, transmission electron microscope. The prepared nanoparticles were subjected to photoluminescence studies and, later, photocatalytic evaluation for the degradation of methylene blue dye.

\section{Materials and Methods}

All materials were obtained from commercial sources. Sodium hydroxide pellets $(\mathrm{NaOH})(98 \%)$ were purchased from Alfa Aesar, Karlsruhe, Germany. Hydrochloric acid $(\mathrm{HCl})(\sim 36 \%)$ and methylene blue were purchased from Sigma-Aldrich. All reagents were used as received without any further treatment. Deionized water was used throughout the experimental process.

\subsection{Experimental}

Preparation of S. persica Extract

Fresh S. persica leaves were collected from a local farm in Al Amaaria, Riyadh, Saudi Arabia. A total of $30 \mathrm{~g}$ of leaves was washed several times with tap water and distilled water. The leaves were dried in the shade at room temperature for two days and then powdered using a mixer. The resulting powder was extracted from the reflux extraction using $150 \mathrm{~mL}$ of water as a solvent.

\subsection{Synthesis of $\mathrm{ZnO}$ Nanoparticles}

In the present study, the desired $\mathrm{ZnO}$ nanoparticles were synthesized using two approaches, as described below and shown in Scheme 2 .
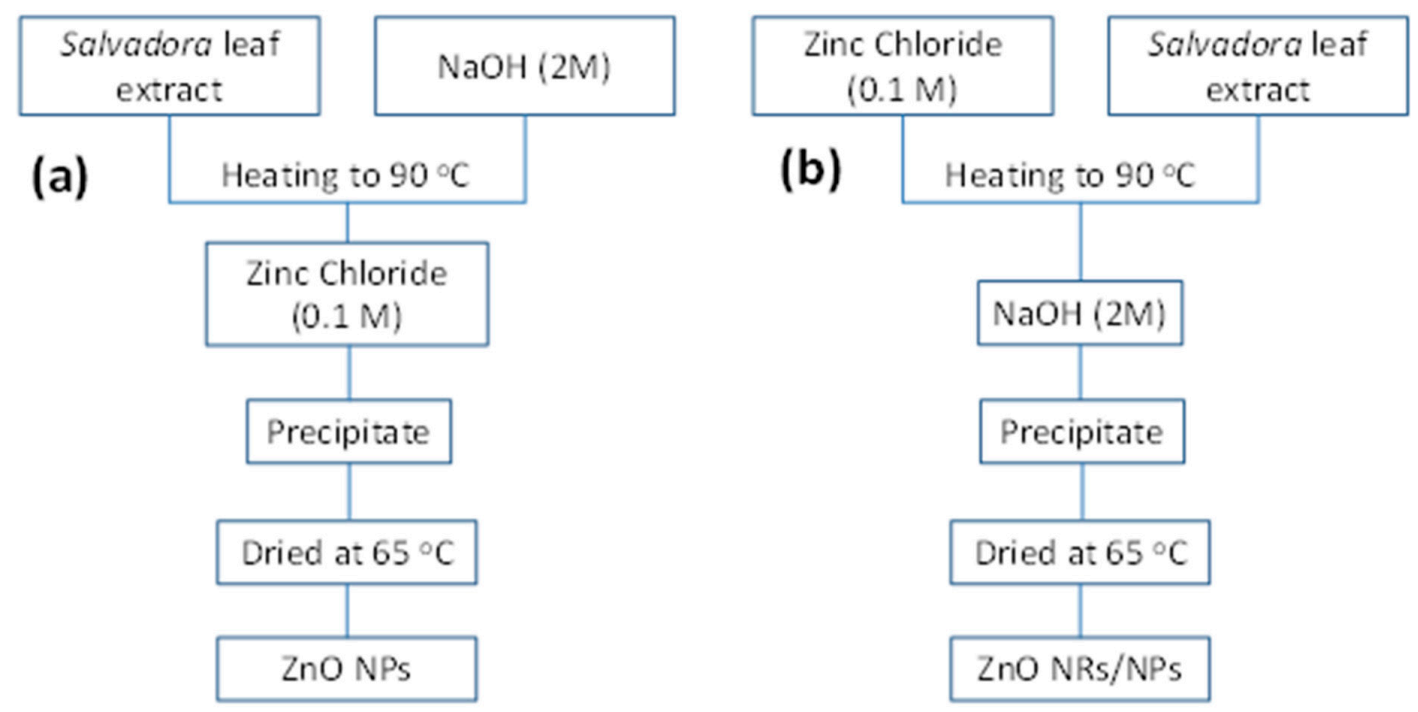

Scheme 2. Flow chart of the two different synthetic protocols applied for the synthesis of $\mathrm{ZnO}$ nanoparticles.

\subsubsection{Procedure (a)}

In this procedure, to $100 \mathrm{~mL}$ of $S$. persica leaf extract was added $2 \mathrm{M}$ sodium hydroxide until a pH of 12 was attained and the solution was heated to $90{ }^{\circ} \mathrm{C}$ under constant stirring. Once the desired temperature was attained, $100 \mathrm{~mL}$ of zinc chloride $(0.1 \mathrm{M})$ was added dropwise and the resultant solution was continually stirred at $90^{\circ} \mathrm{C}$ for $4 \mathrm{~h}$. The mixture was then cooled down to room temperature subjected to centrifugation, washed twice with distilled water, and dried in an oven at $65^{\circ} \mathrm{C}$ overnight. The $\mathrm{ZnO}$ nanoparticles obtained were labeled A1. 


\subsubsection{Procedure (b)}

In this procedure, $100 \mathrm{~mL}$ of zinc chloride $(0.1 \mathrm{M})$ solution was heated to $90{ }^{\circ} \mathrm{C}$ under constant stirring, to which $100 \mathrm{~mL}$ of $S$. persica leaf extract was added dropwise and heated for $4 \mathrm{~h}$. Later sodium hydroxide ( $2 \mathrm{M}$ ) solution was added until $\mathrm{pH} 12$ was reached. The mixture was cooled down to RT, subjected to centrifugation, washed twice with distilled water, and dried in an oven at $65{ }^{\circ} \mathrm{C}$ overnight. The $\mathrm{ZnO}$ nanoparticles obtained were labeled B1.

\subsection{Photocatalytic Activity}

The photo-reactor "Heber" was purchased from Chennai, India. The photocatalytic reactor consisted of a medium-pressure mercury vapor lamp $(\lambda \max =365 \mathrm{~nm}, 250 \mathrm{~W})$ in a jacketed quartz crystal tube; the heat caused by the lamp was removed by the continuous circulation of cold water throughout the jacket. The 37-cm-long tube with an inner diameter of $2.3 \mathrm{~cm}$ and an outer diameter of $2.7 \mathrm{~cm}$ had a capacity of $100 \mathrm{~mL}$.

The gap between the mercury lamp and the quartz tube containing pollutant was $6 \mathrm{~cm}$. The uniform distribution of catalytic particles throughout the solution was achieved using an air pump [38]. The solution was continuously boiled in the dark for $30 \mathrm{~min}$ to ensure the organization of an adsorption-desorption equilibrium between the $\mathrm{MB}$ and photocatalyst prior to irradiation by a light source. Over $30 \mathrm{~min}$ intervals, $2 \mathrm{~mL}$ of the suspension was withdrawn from the reactor, and the solution was centrifuged to remove the $\mathrm{ZnO}$ nanoparticles from the mixture. The dye concentration of leftover aqueous solution was measured using a UV-Vis spectrophotometer at $664 \mathrm{~nm}$. The degradation of the MB was calculated using the following equation:

$$
\% \text { of degradation }=\frac{C_{i}-C_{f}}{C_{i}} \times 100
$$

where $C_{i}$ and $C_{f}$ are the initial and final concentrations of dye in ppm, respectively. The photocatalytic experiment was repeated by changing various parameters, such as catalytic load, concentration of dye, $\mathrm{pH}$, variation, catalyst recycling, etc.

\subsection{Characterization}

The synthesized nanoparticles were characterized using powder X-ray diffraction (XRD; Rigaku Smart Labs). Fourier-transform infrared spectroscopy (FT-IR; Thermo Scientific Nicole iS10) was used to analyze the metal oxide bond-stretching frequencies. The UV-visible spectrum of the samples was measured using a UV-visible (UV-Vis) spectrophotometer (Lab India-Diffuse reflectance spectra and Cary 60 Agilent technologies-absorbance spectra). The morphologies of the prepared nanoparticles were scanned using scanning electron microscopy (SEM; JEOL JSM-6380 LA). The shape and size of the $\mathrm{ZnO}$ crystallites were determined using a transmission electron microscope (TEM; JEOL JEM-1011). Photoluminescence studies were recorded using the Cary Eclipse fluorescence spectrophotometer (Agilent).

\section{Results and Discussion}

\subsection{ZnO Nanostruture Characterization}

\subsubsection{Microscopic Analysis}

\section{1) Scanning Electron Microscopy Analysis}

Figure 1 demonstrates the SEM images of compounds A1 (Figure 1a,b) and B1 (Figure 1c,d). From an evaluation of the surface morphology, it is evident that the change in procedure resulted in different surface morphologies of the $\mathrm{ZnO}$ nanoparticles. Procedure (a), wherein the Zinc precursor was added to the solution of S. persica leaf extract at $\mathrm{pH} 12$, yielded a rugged surface morphology, 
whereas procedure (b), wherein the Zinc precursor was added to the solution of S. persica leaf extract and later the $\mathrm{pH}$ of the solution was changed to 12, yielded a rugged surface morphology with a rod-like structure.
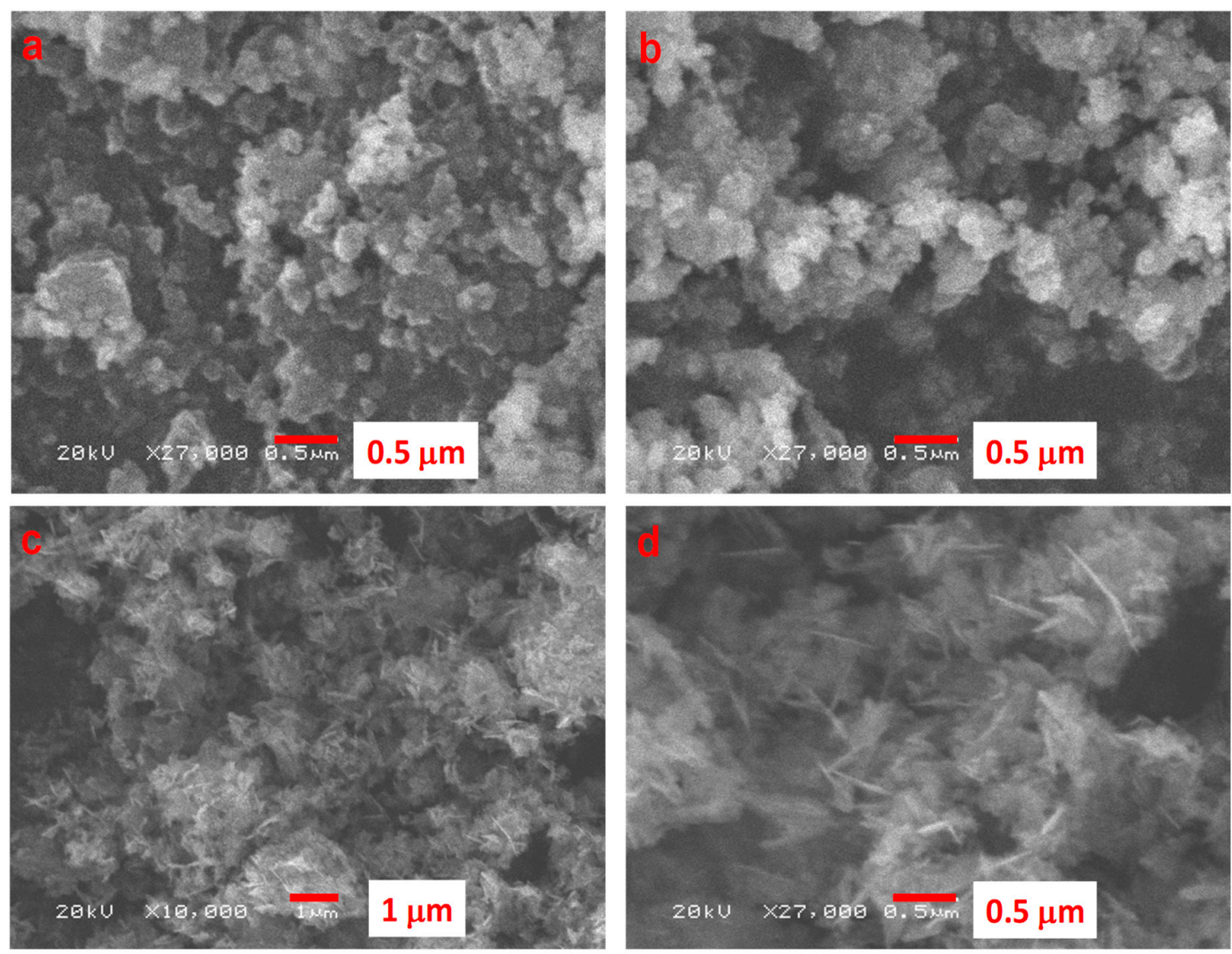

Figure 1. (a,b) SEM images of $\mathrm{ZnO}$ nanoparticles prepared.by procedure (a); (c,d) SEM images of ZnO nanoparticles prepared by procedure (b) using $S$. persica leaf extract.

\section{2) Transmission Electron Microscopy}

Further studies using transmission electron microscopy shed further light on the effect of different procedures on the size and shape of the $\mathrm{ZnO}$ nanoparticles obtained using $\mathrm{S}$. persica leaf extract by the sol-gel method. The microscopic images obtained are illustrated in Figure 2 As seen in Figure 2a,b, the $\mathrm{ZnO}$ nanoparticles prepared employing procedure (a) were found to be of a spherical in shape, with a size of about 30 to $50 \mathrm{~nm}$, with some instances of agglomeration leading to the formation of honeycomb-like structures. However, with the change in the synthetic pathway (i.e., procedure (b)), some of the nanoparticles obtained were found to be shaped like nanorods in the nanoparticle mixture obtained. The lengths of the nanorods were in the range of 230 to $400 \mathrm{~nm}$, and their width varied from 25 to $35 \mathrm{~nm}$. Furthermore, sheet-like structures with nanocavities caused due to the plant extract were clearly observed (Figure 2). These structures absorbed the light more efficiently, which cause light sensitivity [39]. 

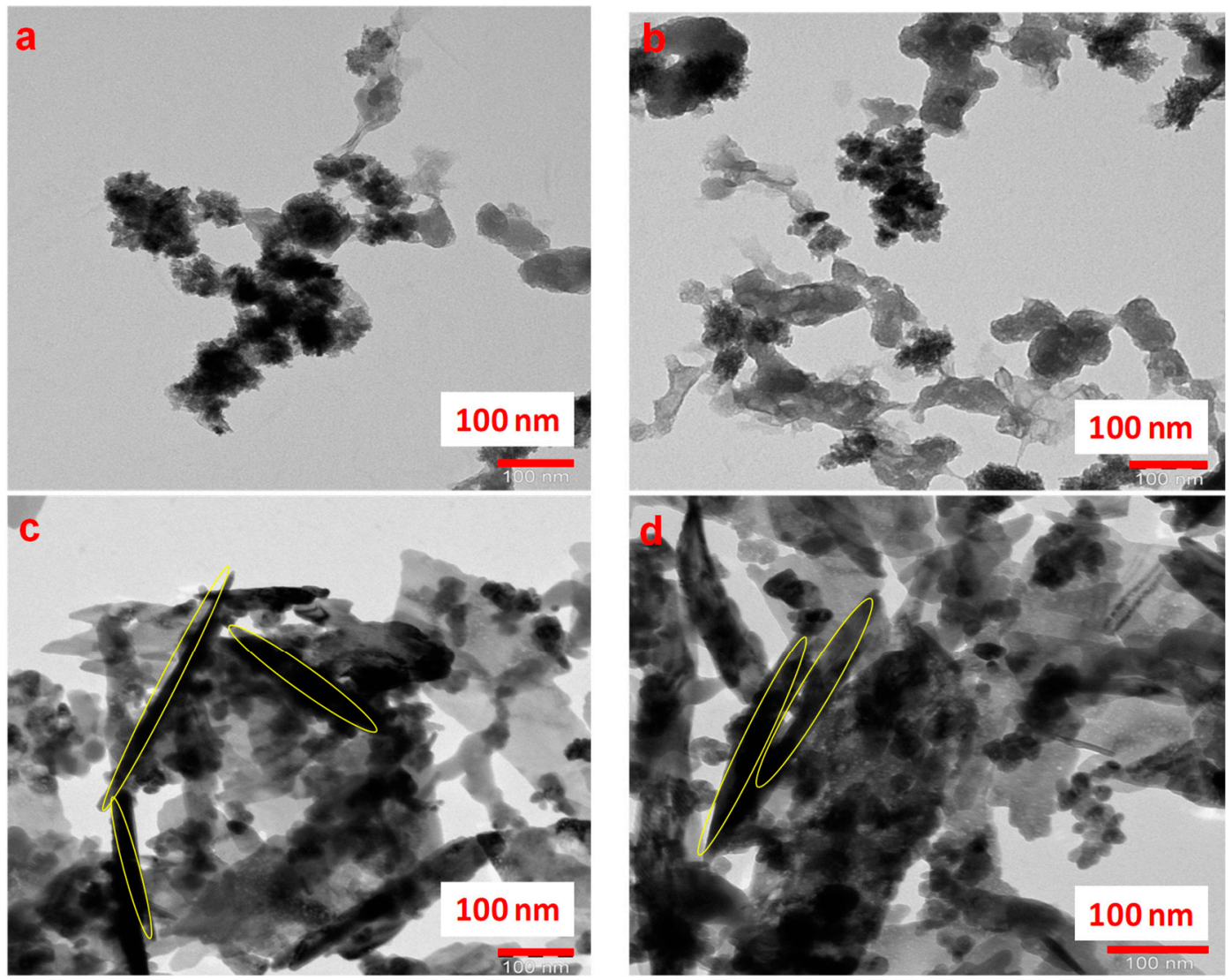

Figure 2. (a,b) Transmission electron microscopy (TEM) images of ZnO nanoparticles (A1) prepared.by procedure (a); (c,d) TEM images of $\mathrm{ZnO}$ nanoparticles (B1) prepared by procedure (b) using S. persica leaf extract.

From the microscopic analysis, it can be concluded that the different protocols resulted in different morphologies of $\mathrm{ZnO}$ nanoparticles obtained. The protocol wherein the S. persica leaf extract was heated with $2 \mathrm{M} \mathrm{NaOH}$ at $90^{\circ} \mathrm{C}$, followed by the addition of the $\mathrm{ZnCl}_{2}$, produced the $\mathrm{ZnO}$ nanoparticles in Scheme 2a. However, the protocol wherein the S. persica leaf extract was heated with $\mathrm{ZnCl}_{2}$, followed by the addition of $\mathrm{NaOH}$, yielded a mixture of $\mathrm{ZnO}$ nanorods and nanoparticles. From the results obtained, it can be concluded that the S. persica leaf extract, plays a very efficient role as a surfactant and capping agent, wherein it controls the morphology of the nanoparticles obtained based on the approach adopted. The probable hypothetical mechanism for the role of the plant extract is depicted in Scheme 3.

Figure 3 shows the TEM, HR-TEM, and selected area electron diffraction (SAED) patterns of B1. As seen in Figure 3a,b, sheet-like structures were visible, along with nanorods and nanoparticles, which could be the plant extract that acts as a capping agent, retaining the rod-like morphology of the $\mathrm{ZnO}$ nanorods formed. Figure $3 c$ shows an HR-TEM image of material B1 and reveals a d-spacing value of $0.145 \mathrm{~nm}$ belonging to plane (103). The SAED pattern confirmed that B1 was crystalline in nature (Figure 3d); these reflection fringes that emerged from the particular planes were well matched with the $\mathrm{d}$-spacing values obtained by HR-TEM and were later confirmed by XRD. 


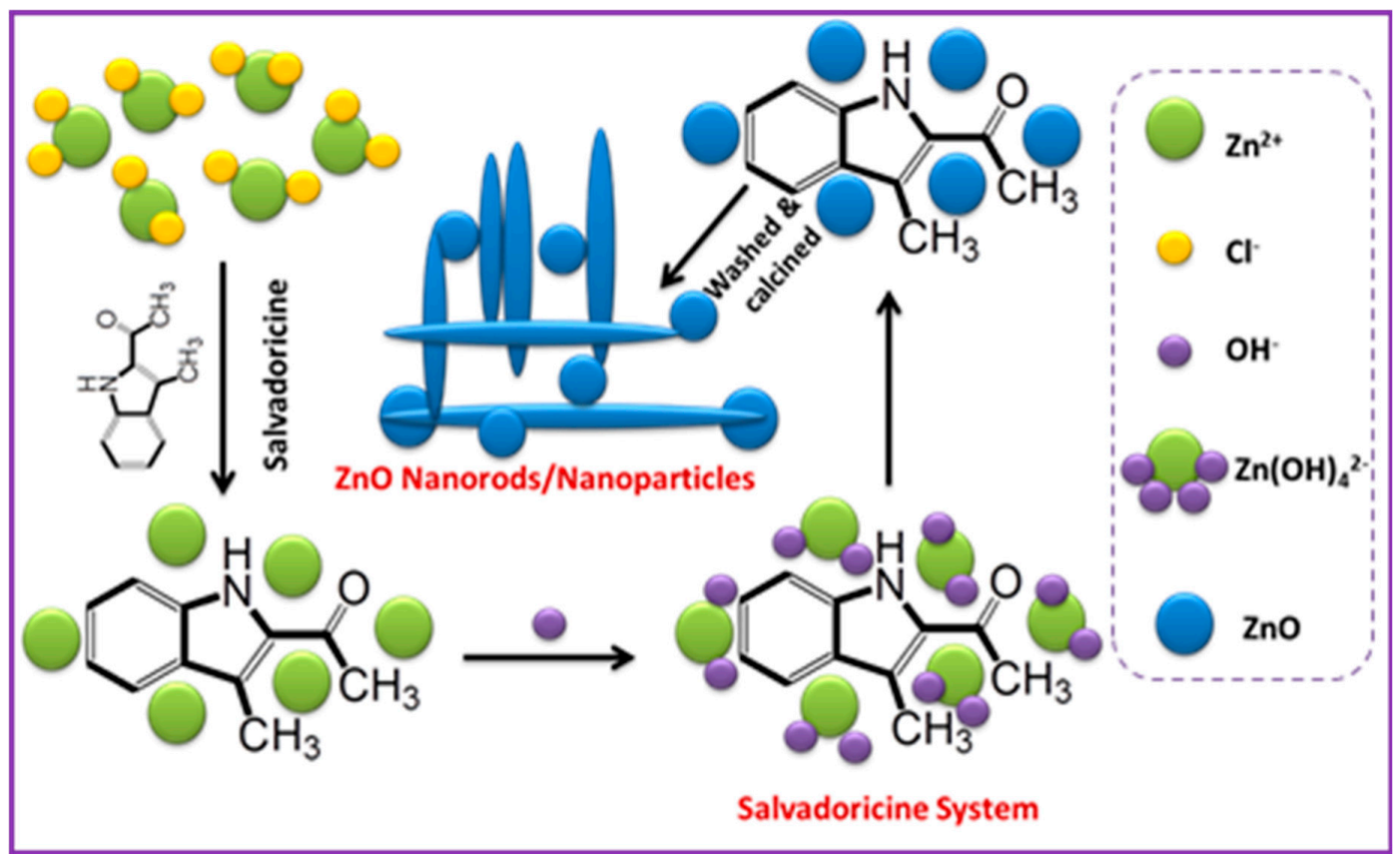

Scheme 3. Schematic representation of the role of phytomolecules of $S$. persica leaf extract in the synthesis process of $\mathrm{ZnO}$ nanorods/nanoparticles.

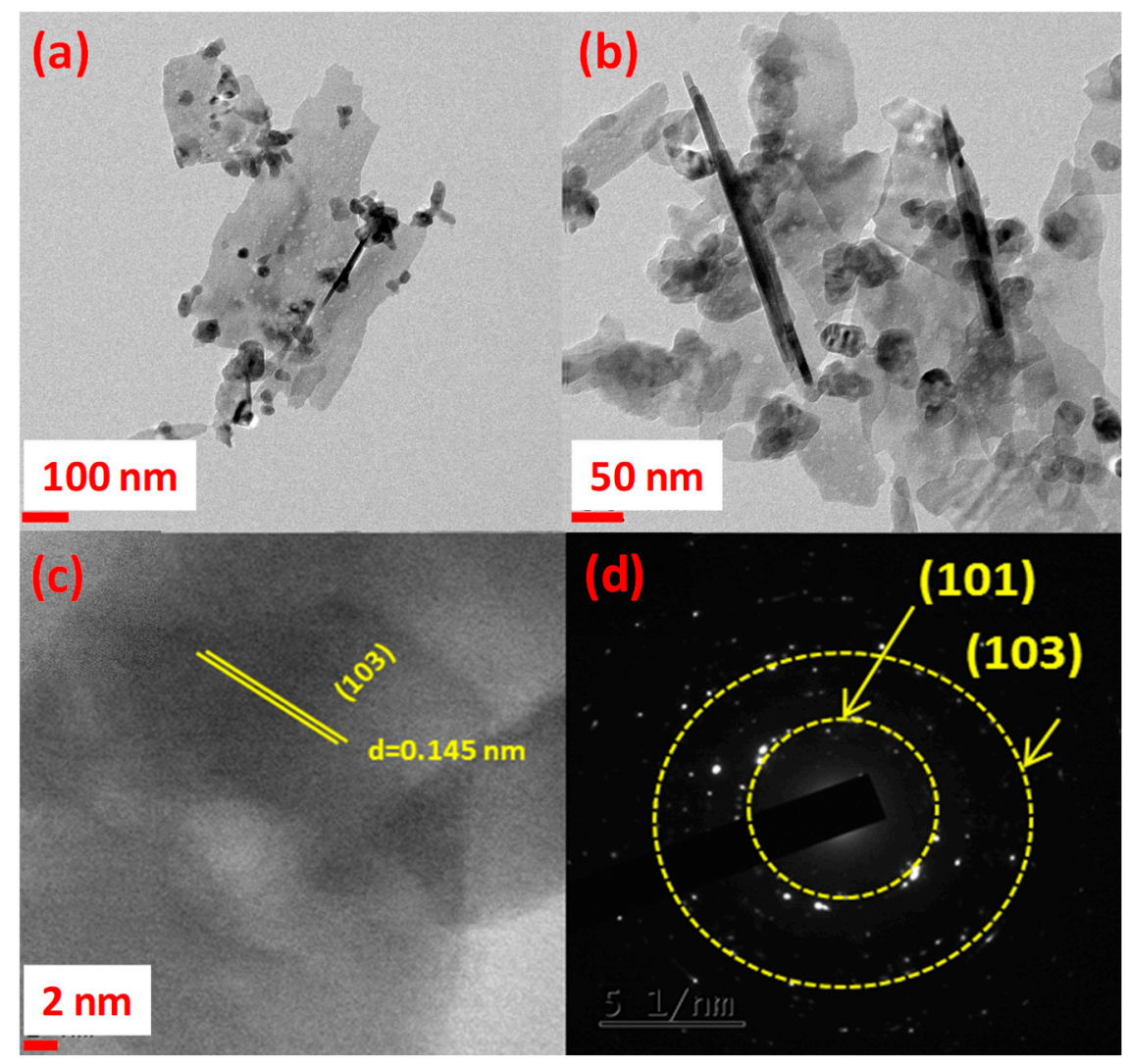

Figure 3. (a), (b) TEM images. (c) HR-TEM images. (d) SAED pattern of material of S. persica leaf extract. 


\subsubsection{Spectral Analysis}

1) XRD Analysis

Figure 4 shows the XRD patterns of materials A1 and B1. The materials were synthesized in different ways using S. persica leaf extract. The XRD results indicated that $\mathrm{ZnO}$ nanoparticles were highly crystalline and had a hexagonal wurtzite structure, resembling the standard JCPDC card number 36-1451 in the space group P63mc. No extra peaks were found in the pattern, which indicated the purity of the samples.

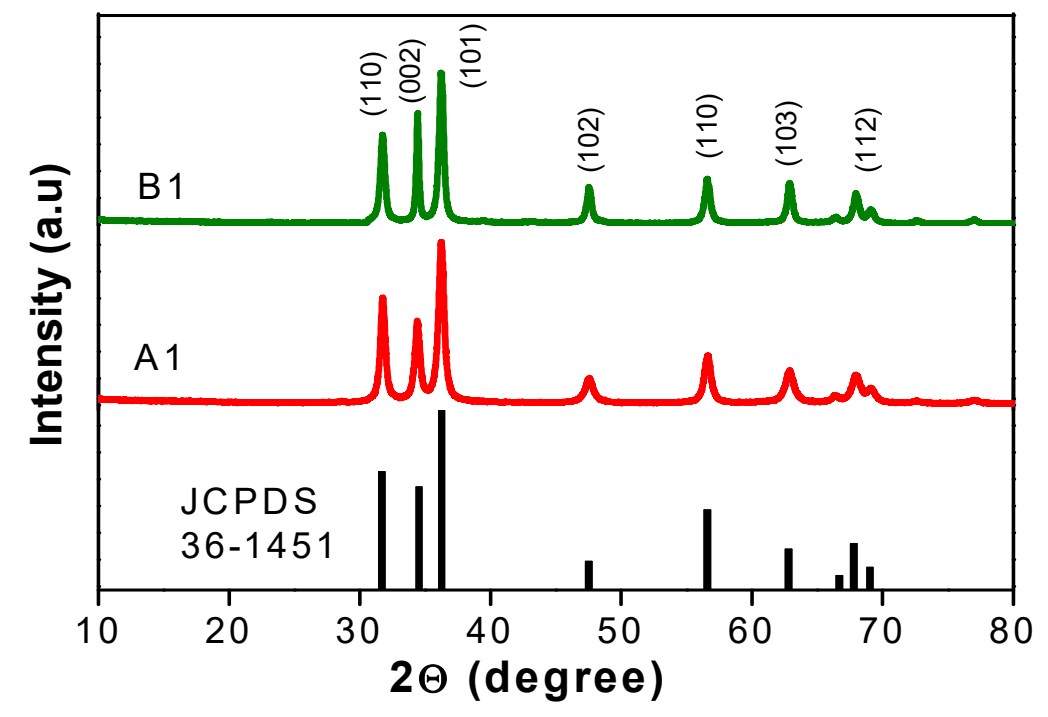

Figure 4. XRD pattern of A1 and B1 synthesized using S. persica leaf extract.

\section{2) FT-IR Analysis}

The FT-IR spectra of the $\mathrm{ZnO}$ nanomaterials were recorded in the range from 4000 to $400 \mathrm{~cm}^{-1}$, as shown in Figure 5. The board peaks at $3425 \mathrm{~cm}^{-1}$ demonstrate the $\mathrm{O}-\mathrm{H}$ bonds of phenols and the peaks at $1600 \mathrm{~cm}^{-1}$ and $1417 \mathrm{~cm}^{-1}$ correspond to the $\mathrm{C}=\mathrm{O}$ stretch in polyphenols and $\mathrm{C}-\mathrm{N}$ stretch in primary amines, respectively. Obtainable weak peaks at 1087 and 850 confirm the presence of $\mathrm{C}-\mathrm{O}$ stretching in amino acid and $\mathrm{C}-\mathrm{H}$ bending, respectively. The peak observed at $569 \mathrm{~cm}^{-1}$ corresponds to the vibrational mode of $\mathrm{ZnO}$ bonding. The above inference justifies the fact that the presence of phenols, polyphenols and primary amines in the plant extract could be implicated for the capping and stabilization of $\mathrm{ZnO}$ nanomaterials [40].

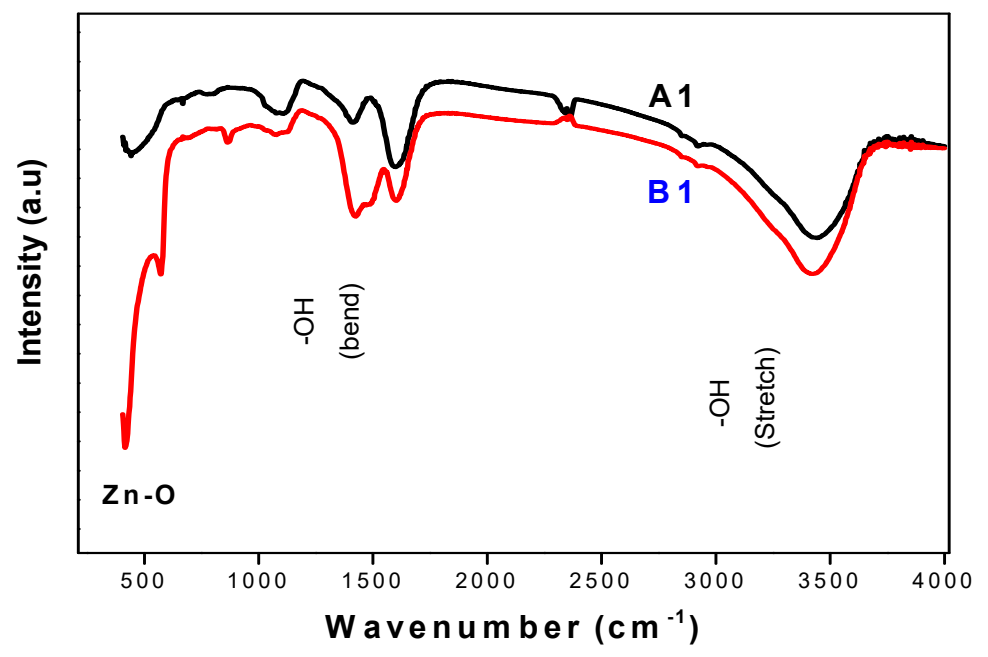

Figure 5. FT-IR spectra of A1 and B1 synthesized using S. persica leaf extract. 
3) UV-Visible diffuse reflectance studies

Figure 6 shows the UV-visible spectra of $\mathrm{ZnO}$ nanoparticles synthesized by the green sol-gel method using S. persica leaf extract. The spectra demonstrated an absorption band at around $378 \mathrm{~nm}$. Because of the electron transfer from the valence band to the conduction band, by using the Kubelka-Munk relation, the calculated Eg values were found to be 3.3 and $3.26 \mathrm{eV}$ for A1 and B1, respectively [41] (Figure 6b). The higher band gap indicates the formation of smaller NPs; however, it also means that there is a greater restriction of movement on electrons. From this, it can be concluded that sample B1 has a better conductance, which may be the reason for its better photocalytic performance, as described below.
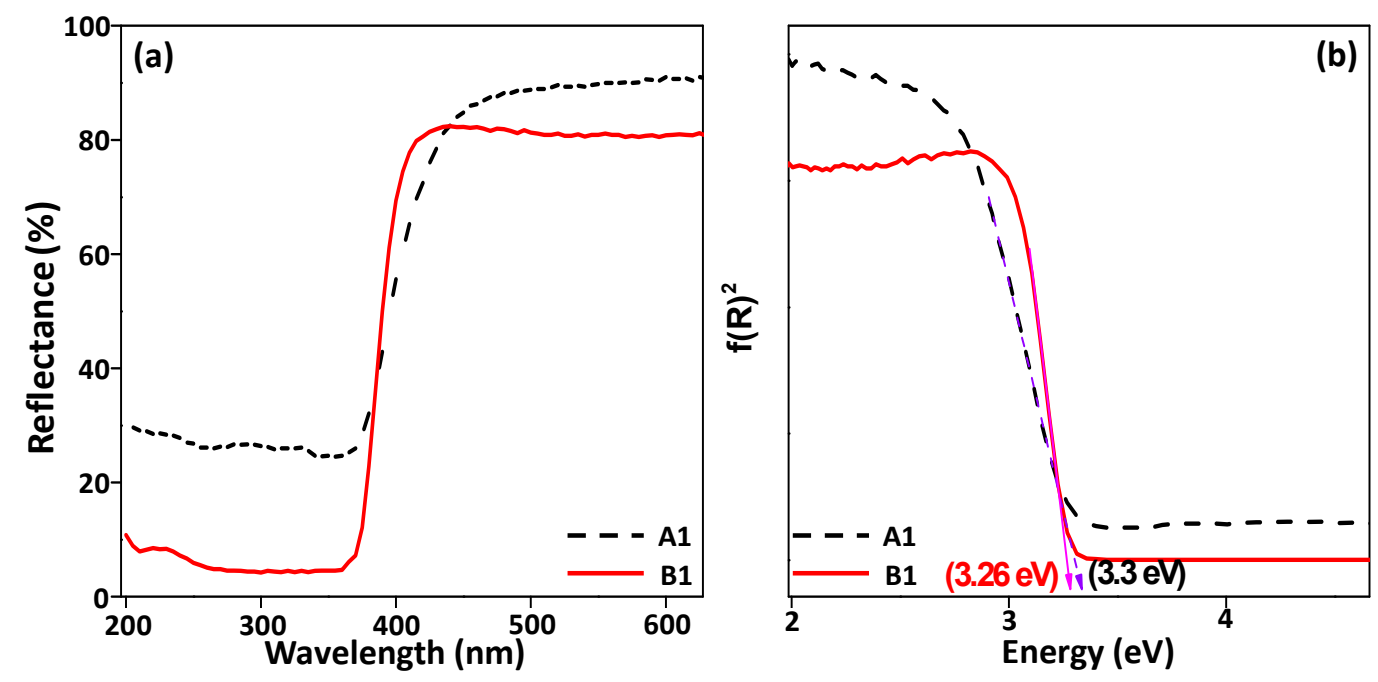

Figure 6. (a) UV-visible diffuse reflectance spectrum. (b) Bandgap calculation graph.

\subsection{Photocatalytic Activity of $\mathrm{ZnO}$ Nanostructres}

\subsubsection{Degradation of Methylene Blue}

Under UV irradiation, a semiconductor absorbs photon energy equal to or greater than the bandgap of the semiconductors, which results in the generation of electrons and holes on the surface of the photocatalyst. If the charge carriers do not recombine, they migrate to the surface, wherein in the presence of $\mathrm{O}_{2}$ and $\mathrm{H}_{2} \mathrm{O}$, ends up forming four major reactive oxygen species (ROSs), which are hydroxyl radical $(\bullet \mathrm{OH})$, superoxide anion radical $\left(\bullet \mathrm{O}_{2}^{-}\right)$, singlet oxygen $\left({ }^{1} \mathrm{O}_{2}\right)$ and hydrogen peroxide $\left(\mathrm{H}_{2} \mathrm{O}_{2}\right)$ [42].

This $\mathrm{OH}^{\bullet}$ (hydroxyl radical) formed species is highly reactive and unstable. It ultimately acts on organic compounds and oxidizes carcinogenic dyes to $\mathrm{CO}_{2}$, water, and inorganic acids. The photocatalytic action of the catalyst on the dye was reportedly enhanced by various factors, such as the particle size of the catalyst, phase composition, shape, crystallinity, size distribution, surface area, surface $\mathrm{OH}$ group density and bandgap [43]. A photocatalytic evaluation of the as-synthesized $\mathrm{ZnO}$ nanorods/nanoparticles was carried out, employing them as catalysts for the degradation of methylene blue under UV rays, in a UV-Vis reactor. The progress of the reaction was carried out by periodic collection, i.e., every $30 \mathrm{~min}$, with $2 \mathrm{~mL}$ aliquots of the reaction mixture, which were centrifuged to remove the suspended $\mathrm{ZnO}$ nanorods/nanoparticles. The absorption spectrum of the reaction mixture was then recorded using a UV-Vis spectrophotometer. Upon evaluation of the results obtained, it was found that the B1 displayed a degradation efficiency of $95 \%$ within 150 min of exposure time, whereas the sample A1 showed a degradation efficiency of about $75 \%$. A graphical representation of the results obtained are given in Figure 7. The enhanced photocatalytic activity of B1 can be attributed to the presence of nanocavities and the nanorods of $\mathrm{ZnO}$ (lengthy, spindle-like structures) on the surface of the $\mathrm{ZnO}$ nanoparticles. 


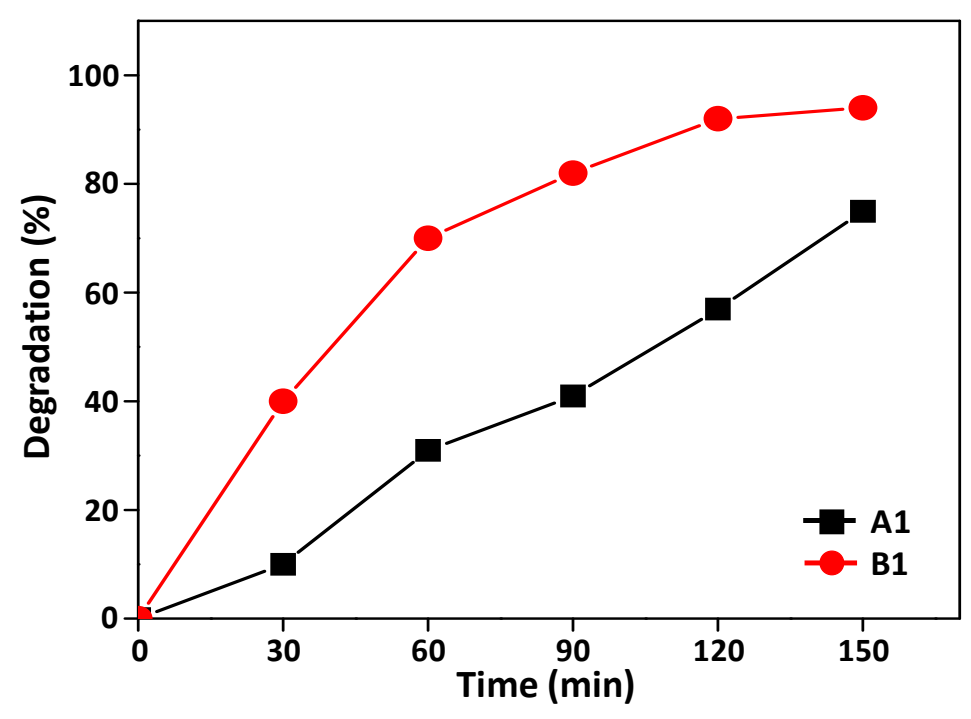

Figure 7. Degradation efficiency of catalysts A1 and B1.

\subsubsection{Mechanism of Photodegradation}

$\mathrm{OH}^{\bullet}$ ions are an unstable and reactive chemical species that play an important role in the degradation of organic dyes. In order to identify whether the $\mathrm{OH}^{\bullet}$ free radical is being generated by the photocatalyst $\mathrm{B} 1$, coumarin was used as a probe molecule, which is a simple and sensitive approach for $\mathrm{OH}^{\bullet}$ detection. In the presence of an $\mathrm{OH}^{\bullet}$ ion generated by the photocatalyst, coumarin converts to 7-hydroxyl coumarin, a luminous material that exhibits a photoluminescent peak at $455 \mathrm{~nm}$ wavelength. In this study, $100 \mathrm{mg}$ of the catalyst (B1) was added to $50 \mathrm{~mL}$ of $1 \mathrm{mM}$ coumarin solution irradiated by a 120-W UV source. At an interval of $10 \mathrm{~min}, 2 \mathrm{~mL}$ of the aliquot sample was withdrawn and measured using a photoluminescence spectrometer, which revealed the production of $\mathrm{OH}^{\bullet}$ free radicals, a vital species for the degradation of organic dyes [44]. Moreover, it was observed that, as the irradiation time increases, the intensity of the peak/band increases at $455 \mathrm{~nm}$, which indicates that, as the exposure time increases, there is a steady production of $\mathrm{OH}^{\bullet}$ radicals, as well as an increase in the rate of production in the system. (Figure 8) Hence, it can be confirmed that the degradation of methylene blue takes place via a free radical mechanism in the presence of a catalyst (B1).

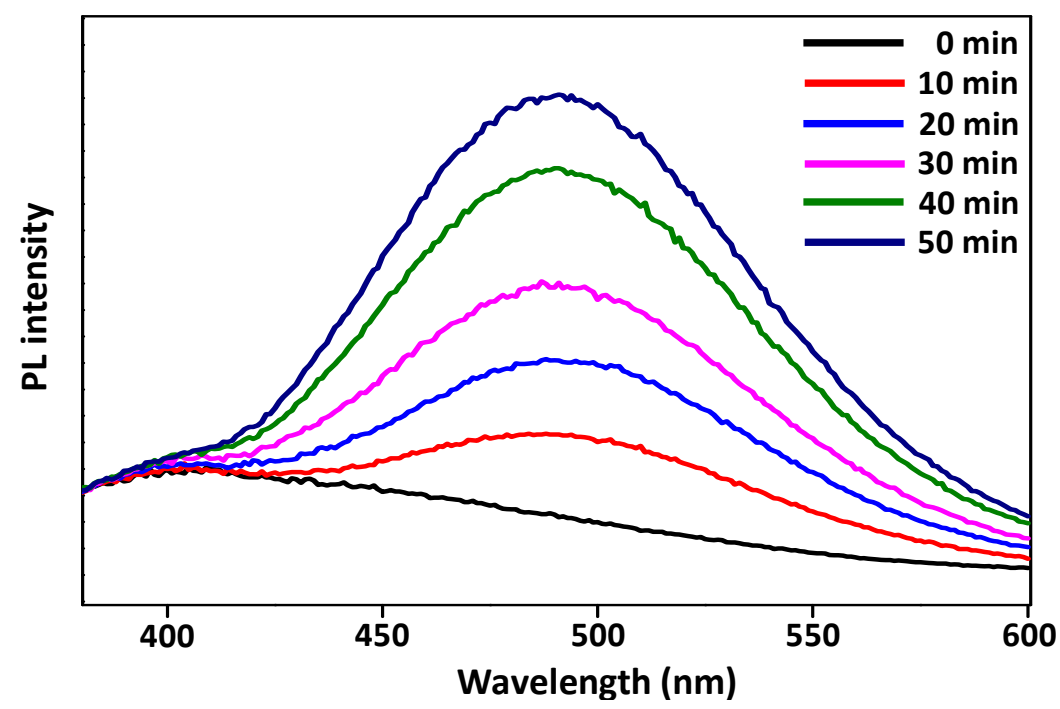

Figure 8. Photoluminescence spectrum indicating generation of $\mathrm{OH}^{\bullet}$ ion by $\mathrm{B} 1$ at different time intervals. 


\subsection{Optimization Studies}

Since the $\mathrm{ZnO}$ nano rods and nanoparticles (B1) yielded the best photocatalytic activity, they were selected for further optimization studies in order to find out the optimum dye concentration, catalyst loading and $\mathrm{pH}$. The prepared nanocatalyst was also subjected to recycling studies to evaluate its stability.

\subsubsection{Effect of Dye Concentration}

The photocatalytic activity of $\mathrm{ZnO}$ nanoparticles was also affected by the concentration of the dye. To determine the optimum concentration of dye required for efficient oxidation, an experiment was performed with the catalyst (B1) load $(10 \mathrm{mg})$ kept constant, while the dye concentration varied from 5 ppm to 25 ppm, as shown in Figure 9. Under the UV light, it was observed that, upon increasing the dye concentration from $5 \mathrm{ppm}$ to $20 \mathrm{ppm}$, the photocatalytic degradation of catalyst B1 reduced from $100 \%$ to $82 \%$. The 5-ppm dye concentration showed the highest photocatalytic degradation activity (i.e., $100 \%$ ) within $2.5 \mathrm{~h}$ of UV exposure. Generally, as the concentration of the dye increases, the penetration of light through the dye solution decreases; therefore, more dye molecules are adsorbed on the surface of the catalyst. Because of this effect, the production of $\mathrm{OH}^{\bullet}$ and $\mathrm{O}_{2}{ }^{2-}$ in the solution mixture decreased, which lowered the degradation efficiency [45].

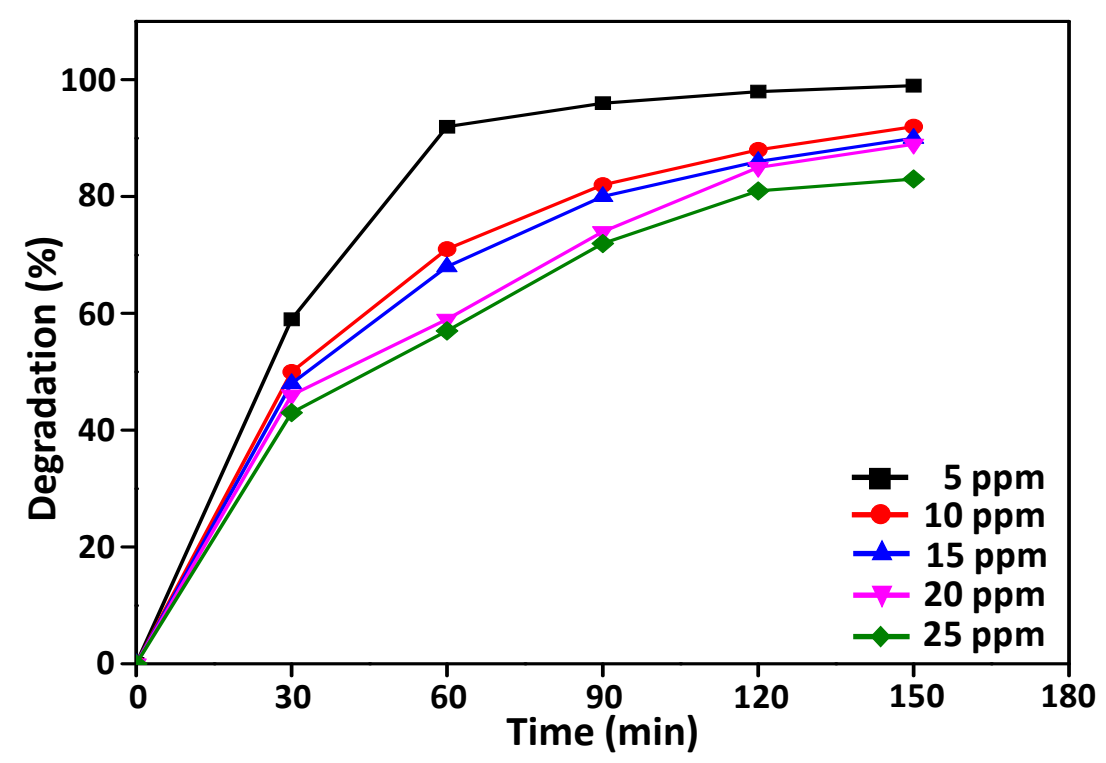

Figure 9. Degradation of MB with varying dye concentration and a constant catalyst load (B1).

\subsubsection{Effect of Catalyst Load}

In general, increasing the photocatalyst load in the reaction system would lead to a higher production of $\mathrm{OH}^{\bullet}$ free radicals, due to the increased light absorption, which, in turn, causes increased catalytic activity. In this study, the oxidative degradation of methylene blue was carried out by varying the catalyst (B1) load from 5 to $25 \mathrm{mg}$, while the dye concentration was kept constant (5 ppm). In $150 \mathrm{~min}$, the degradation of the dye increased from $88 \%$ to $100 \%$, while the catalyst load increased from 5 to $10 \mathrm{mg}$; however, upon a further increase in the catalyst load up to $25 \mathrm{mg}$, the degradation efficiency of the dye was found to decrease to $<90 \%$. This could be attributed to the light scattering and screening effects, which arise due to the increase in the catalyst load in the reaction system, which results in a reduction in the catalytic performance [46,47]. In addition, catalyst aggregation might also reduce the catalytic activity [47]. Consequently, in this work, the optimal amount of B1 catalyst to reach the best degradation rate was found to be $10 \mathrm{mg}$. Figure 10 shows the degradation kinetics of methylene blue by varying the catalyst load ( 5 to $25 \mathrm{mg} \mathrm{B} 1$ ) at a constant dye concentration (5 ppm). 


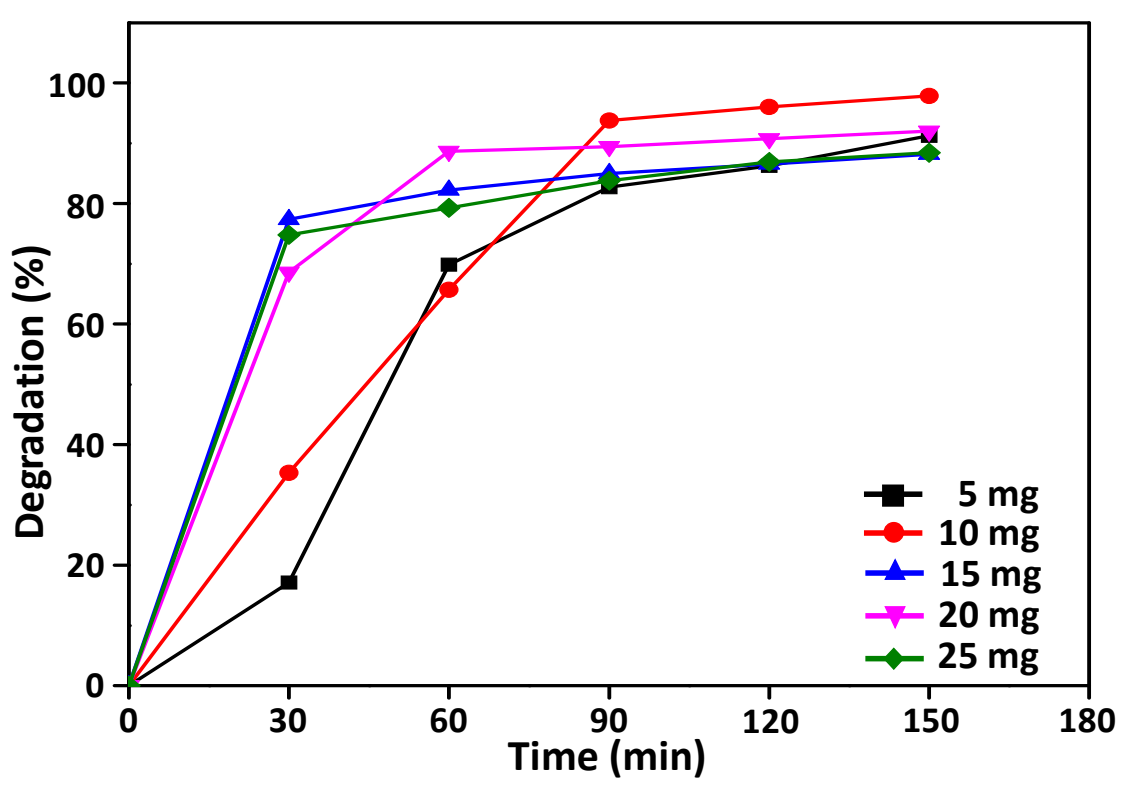

Figure 10. Degradation of MB with varying catalyst loads (B1) and constant dye concentration.

\subsubsection{Effect of $\mathrm{pH}$}

To optimize the $\mathrm{pH}$ for the efficient photodegradation of methylene blue, experiments were performed at different $\mathrm{pH}$ levels (2 to 12), while keeping the catalyst load (B1) and dye concentration constant. The results are shown in Figure 11. These experiments revealed that the degradation of methylene blue was effective in a basic medium [44,48,49], and the highest degradation rate was observed at $\mathrm{pH} 10$. Above this $\mathrm{pH} 10$, the degradation decreased and could be explained based on the zero-potential charge (ZPC). For $\mathrm{ZnO}$, the $\mathrm{ZPC}$ was $9.0 \pm 0.3$. If the $\mathrm{ZPC}$ is larger than this value, the surface net negative charge is high, due to the increase in the $\mathrm{OH}^{-}$ions adsorbed on the surface. Due to the presence of many $\mathrm{OH}^{-}$ions on the surface of the catalyst, $\mathrm{OH}^{\bullet}$ free radical generation is lowered, a radical species that is the primary oxidant responsible for the degradation of methylene blue [49].

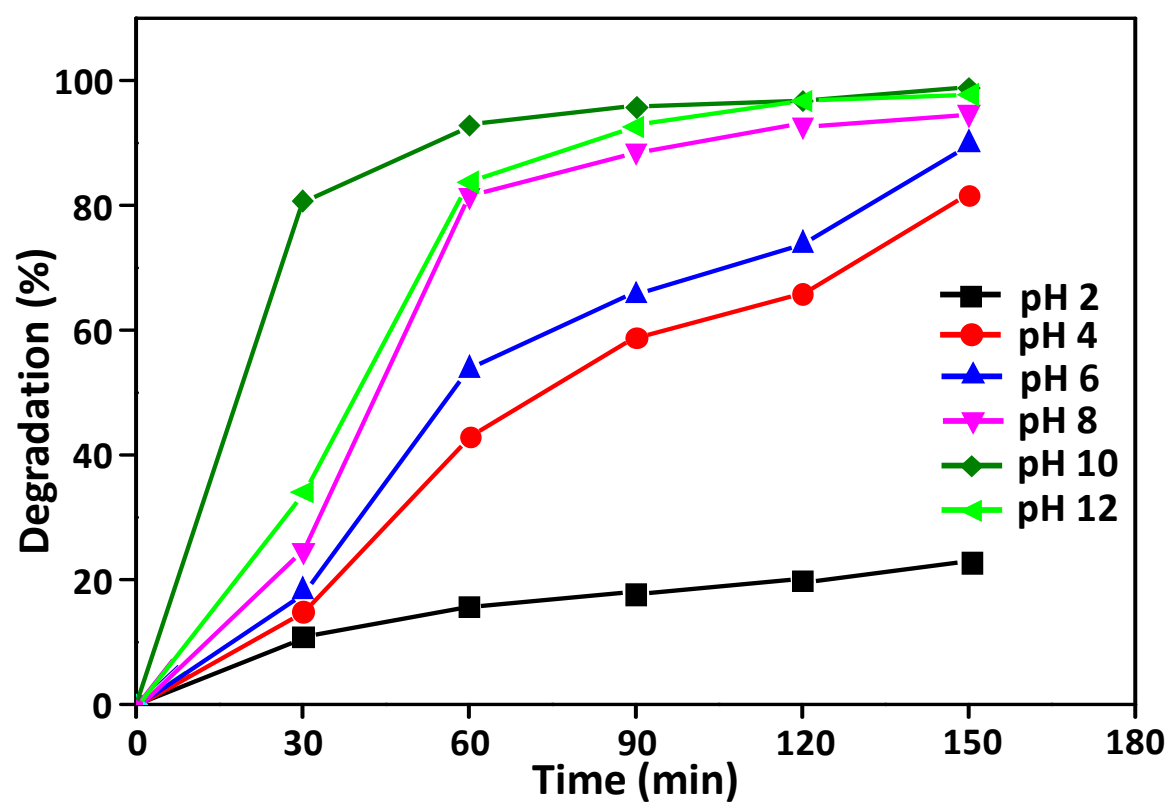

Figure 11. Degradation of $\mathrm{MB}$ with varying $\mathrm{pH}$ in the solution, constant catalyst load (B1) and dye. 


\subsubsection{Catalyst Recycling}

The recyclability experiment of catalyst B1 was carried out using $10 \mathrm{mg}$ of catalyst, in a dye concentration of $5 \mathrm{ppm}$ at $\mathrm{pH} 7$ and the catalyst was reused for about five cycles. After UV light irradiation for $150 \mathrm{~min}$, each of the photodegradation mixtures was centrifuged and filtered. The catalyst B1 residue was washed several times with distilled water. Recovered B1 was then reused for a new photodegradation batch, without any further treatment. From the outcomes of this study, it can be concluded that the catalytic efficiency of the catalyst B1 decreases by $8 \%$ after five cycles of reuse, with an efficiency reduction of $1.5 \%$ after each cycle of reuse. The regeneration stability of nanorods and nanoparticles in the green synthesized $\mathrm{ZnO}$ nanomaterials using S. persica leaf extract can be attributed to the prevention of the oxidative decomposition of the catalyst by the $S$. persica leaf extract, which acts as a capping agent. The results obtained are illustrated in Figure 12.

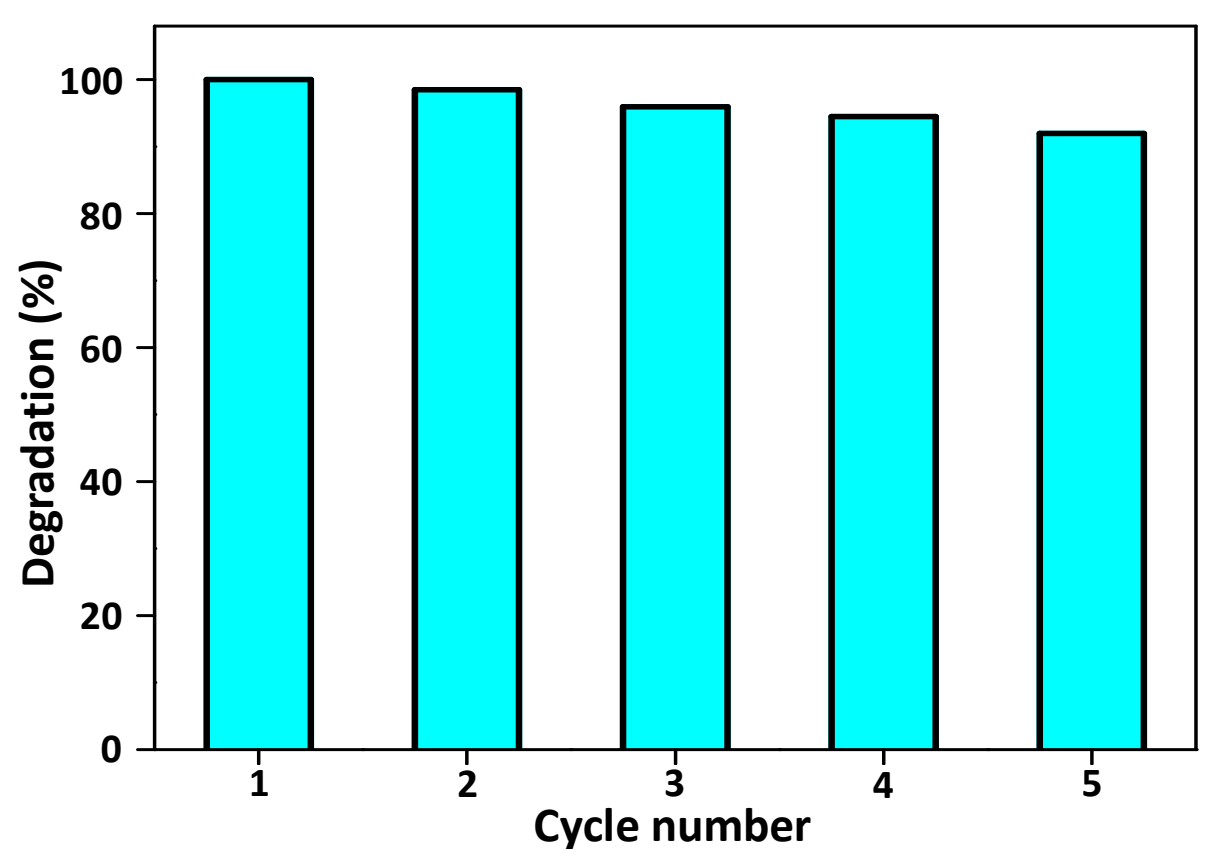

Figure 12. Degradation of MB carried out using recycling of the catalyst load (B1).

\section{Conclusions}

In this study, $\mathrm{ZnO}$ nanorods and nanoparticles were synthesized with a simple green sol-gel method using S. persica extract as a surfactant and capping agent. The XRD pattern showed that the ZnO nanorods/nanoparticles obtained were crystalline in nature and possessed a hexagonal lattice structure with an average crystallite size of $21.5 \mathrm{~nm}$. The SEM and TEM analysis revealed that the morphology of $\mathrm{ZnO}$ nanoparticles depended exclusively on the synthetic pathway chosen. The TEM image showed that the particles were virtually agglomerated rod-like structures with a few agglomerated nanoparticles around them. The prepared $\mathrm{ZnO}$ nanorods/nanoparticles exhibited excellent photocatalytic activity against the photodegradation of methylene blue, indicating that a 10-mg catalyst load and a $\mathrm{pH}$ of 10 are the optimum conditions for the $\mathrm{ZnO}$ nanoparticles to display the best catalytic performance.

Author Contributions: F.A.A. and N.A.-Z. played an important role in the project design and execution, while M.F.A. carried out the experimental work. F.A.A., A.A.A. (Asma A. Alothman) and Z.M.A. played a crucial role in the characterization and elucidation of the results. F.A.A. and A.A.A. (Abdulaziz Ali Alghamdi) compiled the data and prepared the manuscript. All authors read and approved the final manuscript.

Acknowledgments: The authors extend their appreciation to the Deanship of Scientific Research at King Saud University for funding this work through Research Group No. RGP-1438-040.

Conflicts of Interest: The authors declare that they have no conflict of interests. 


\section{References}

1. Parshi, N.; Pan, D.; Dhavle, V.; Jana, B.; Maity, S.; Ganguly, J. Fabrication of lightweight and reusable salicylaldehyde functionalized chitosan as adsorbent for dye removal and its mechanism. Int. J. Biol. Macromol. 2019, 141, 626-635. [CrossRef]

2. Han, F.; Kambala, V.S.R.; Srinivasan, M.; Rajarathnam, D.; Naidu, R. Tailored titanium dioxide photocatalysts for the degradation of organic dyes in wastewater treatment: A review. Appl. Catal. A Gen. 2009, 359, 25-40. [CrossRef]

3. Kołodziejczak-Radzimska, A.; Jesionowski, T. Zinc oxide-From synthesis to application: A review. Materials 2014, 7, 2833-2881. [CrossRef] [PubMed]

4. Sahoo, S.; Maiti, M.; Ganguly, A.; Jacob George, J.; Bhowmick, A.K. Effect of zinc oxide nanoparticles as cure activator on the properties of natural rubber and nitrile rubber. J. Appl. Polym. Sci. 2007, 105, 2407-2415. [CrossRef]

5. Newman, M.D.; Stotland, M.; Ellis, J.I. The safety of nanosized particles in titanium dioxide-and zinc oxide-based sunscreens. J. Am. Acad. Dermatol. 2009, 61, 685-692. [CrossRef] [PubMed]

6. Hatamie, A.; Khan, A.; Golabi, M.; Turner, A.P.; Beni, V.; Mak, W.C.; Sadollahkhani, A.; Alnoor, H.; Zargar, B.; Bano, S. Zinc oxide nanostructure-modified textile and its application to biosensing, photocatalysis, and as antibacterial material. Langmuir 2015, 31, 10913-10921. [CrossRef]

7. Xiao, F.-X.; Hung, S.-F.; Tao, H.B.; Miao, J.; Yang, H.B.; Liu, B. Spatially branched hierarchical ZnO nanorod- $\mathrm{TiO}_{2}$ nanotube array heterostructures for versatile photocatalytic and photoelectrocatalytic applications: towards intimate integration of 1D-1D hybrid nanostructures. Nanoscale 2014, 6, 14950-14961. [CrossRef]

8. Rostami-Charati, F.; Akbari, R. ZnO-nanoparticles as an Efficient Catalyst for the Synthesis of Functionalized Benzenes: Multicomponent Reactions of Sulfonoketenimides. Comb. Chem. High Throughput Screen. 2017, 20, 781-786. [CrossRef]

9. Hosseini-Sarvari, M.; Sharghi, H. ZnO as a new catalyst for N-formylation of amines under solvent-free conditions. J. Org. Chem. 2006, 71, 6652-6654. [CrossRef]

10. Alivov, Y.I.; Kalinina, E.; Cherenkov, A.; Look, D.C.; Ataev, B.; Omaev, A.; Chukichev, M.; Bagnall, D. Fabrication and characterization of $\mathrm{n}-\mathrm{ZnO} / \mathrm{p}-\mathrm{AlGaN}$ heterojunction light-emitting diodes on $6 \mathrm{H}-\mathrm{SiC}$ substrates. Appl. Phys. Lett. 2003, 83, 4719-4721. [CrossRef]

11. Calestani, D.; Zha, M.; Mosca, R.; Zappettini, A.; Carotta, M.; Di Natale, V.; Zanotti, L. Growth of ZnO tetrapods for nanostructure-based gas sensors. Sens. Actuators B Chem. 2010, 144, 472-478. [CrossRef]

12. Lee, K.M.; Lai, C.W.; Ngai, K.S.; Juan, J.C. Recent developments of zinc oxide based photocatalyst in water treatment technology: A review. Water Res. 2016, 88, 428-448. [CrossRef]

13. Li-Xia, L.; Qin-Xin, T.; Chang-Lu, S.; Yi-Chun, L. Structure and photoluminescence of nano-ZnO films grown on a Si (100) substrate by oxygen-and argon-plasma-assisted thermal evaporation of metallic Zn. Chin. Phys. Lett. 2005, 22, 998. [CrossRef]

14. Nagaraju, G.; Ashoka, S.; Chithaiah, P.; Tharamani, C.N.; Chandrappa, G.T. Surfactant free hydrothermally derived $\mathrm{ZnO}$ nanowires, nanorods, microrods and their characterization. Mater. Sci. Semiconduct. Process. 2010, 13, 21-28. [CrossRef]

15. Ashoka, S.; Nagaraju, G.; Tharamani, C.; Chandrappa, G. Ethylene glycol assisted hydrothermal synthesis of flower like $\mathrm{ZnO}$ architectures. Mater. Lett. 2009, 63, 873-876. [CrossRef]

16. Hwang, Y.H.; Seo, S.-J.; Bae, B.-S. Fabrication and characterization of sol-gel-derived zinc oxide thin-film transistor. J. Mater. Res. 2010, 25, 695-700. [CrossRef]

17. Adam, R.E.; Pozina, G.; Willander, M.; Nur, O. Synthesis of ZnO nanoparticles by co-precipitation method for solar driven photodegradation of Congo red dye at different $\mathrm{pH}$. Photonics Nanostruct. Fundam. Appl. 2018, 32, 11-18. [CrossRef]

18. Vabbina, P.K. Sonochemical Synthesis of Zinc Oxide Nanostructures for Sensing and Energy Harvesting. Ph.D. Thesis, Florida International University, Miami, FL, USA, 2016.

19. Vabbina, P.K.; Sinha, R.; Ahmadivand, A.; Karabiyik, M.; Gerislioglu, B.; Awadallah, O.; Pala, N. Sonochemical synthesis of a zinc oxide core-shell nanorod radial p-n homojunction ultraviolet photodetector. ACS Appl. Mater. Interfaces 2017, 9, 19791-19799. [CrossRef] 
20. Alam, F.; Sinha, R.; Jalal, A.H.; Manickam, P.; Vabbina, P.K.; Bhansali, S.; Pala, N. Sonochemically Synthesized Zinc Oxide Nanoflakes Based Electrochemical Immunosensor for Ethyl Glucuronide (EtG) Detection. ECS Trans. 2017, 80, 1287. [CrossRef]

21. Khan, M.; Khan, M.; Adil, S.F.; Tahir, M.N.; Tremel, W.; Alkhathlan, H.Z.; Al-Warthan, A.; Siddiqui, M.R.H. Green synthesis of silver nanoparticles mediated by Pulicaria glutinosa extract. Int. J. Nanomed. 2013, 8, 1507-1516.

22. Khan, M.; Khan, M.; Kuniyil, M.; Adil, S.F.; Al-Warthan, A.; Alkhathlan, H.Z.; Tremel, W.; Tahir, M.N.; Siddiqui, M.R.H. Biogenic synthesis of palladium nanoparticles using Pulicaria glutinosa extract and their catalytic activity towards the Suzuki coupling reaction. Dalton Trans. 2014, 43, 9026-9031. [CrossRef] [PubMed]

23. Adil, S.F.; Assal, M.E.; Khan, M.; Al-Warthan, A.; Siddiqui, M.R.H.; Liz-Marzán, L.M. Biogenic synthesis of metallic nanoparticles and prospects toward green chemistry. Dalton Trans. 2015, 44, 9709-9717. [CrossRef] [PubMed]

24. Khan, M.; Al-Marri, A.H.; Khan, M.; Shaik, M.R.; Mohri, N.; Adil, S.F.; Kuniyil, M.; Alkhathlan, H.Z.; Al-Warthan, A.; Tremel, W. Green approach for the effective reduction of graphene oxide using Salvadora persica L. root (miswak) extract. Nanoscale Res. Lett. 2015, 10, 281. [CrossRef] [PubMed]

25. Khan, M.; Al-Marri, A.H.; Khan, M.; Mohri, N.; Adil, S.F.; Al-Warthan, A.; Siddiqui, M.R.H.; Alkhathlan, H.Z.; Berger, R.; Tremel, W. Pulicaria glutinosa plant extract: A green and eco-friendly reducing agent for the preparation of highly reduced graphene oxide. RSC Adv. 2014, 4, 24119-24125. [CrossRef]

26. Al-Marri, A.H.; Khan, M.; Shaik, M.R.; Mohri, N.; Adil, S.F.; Kuniyil, M.; Alkhathlan, H.Z.; Al-Warthan, A.; Tremel, W.; Tahir, M.N. Green Synthesis of Pd@ Graphene Nanocomposite: Catalyst for the Selective Oxidation of Alcohols. Arabian J. Chem. 2016, 9, 835-845. [CrossRef]

27. Khan, M.; Khan, M.; Al-Marri, A.H.; Al-Warthan, A.; Alkhathlan, H.Z.; Siddiqui, M.R.H.; Nayak, V.L.; Kamal, A.; Adil, S.F. Apoptosis inducing ability of silver decorated highly reduced graphene oxide nanocomposites in A549 lung cancer. Int. J. Nanomed. 2016, 11, 873.

28. Saif, S.; Tahir, A.; Asim, T.; Chen, Y.; Khan, M.; Adil, S.F. Green synthesis of ZnO hierarchical microstructures by Cordia myxa and their antibacterial activity. Saudi J. Biol. Sci. 2019. [CrossRef]

29. Dobrucka, R.; Długaszewska, J. Biosynthesis and antibacterial activity of ZnO nanoparticles using Trifolium pratense flower extract. Saudi J. Biol. Sci. 2016, 23, 517-523. [CrossRef]

30. Ramesh, M.; Anbuvannan, M.; Viruthagiri, G. Green synthesis of $\mathrm{ZnO}$ nanoparticles using Solanum nigrum leaf extract and their antibacterial activity. Spectrochim. Acta Part A Mol. Biomol. Spectrosc. 2015, 136, 864-870. [CrossRef]

31. Sharmila, G.; Thirumarimurugan, M.; Muthukumaran, C. Green synthesis of ZnO nanoparticles using Tecoma castanifolia leaf extract: Characterization and evaluation of its antioxidant, bactericidal and anticancer activities. Microchem. J. 2019, 145, 578-587. [CrossRef]

32. Supraja, N.; Prasad, T.; Krishna, T.G.; David, E. Synthesis, characterization, and evaluation of the antimicrobial efficacy of Boswellia ovalifoliolata stem bark-extract-mediated zinc oxide nanoparticles. Appl. Nanosci. 2016, 6, 581-590. [CrossRef]

33. Mohammadi-Aloucheh, R.; Habibi-Yangjeh, A.; Bayrami, A.; Latifi-Navid, S.; Asadi, A. Green synthesis of $\mathrm{ZnO}$ and $\mathrm{ZnO} / \mathrm{CuO}$ nanocomposites in Mentha longifolia leaf extract: Characterization and their application as anti-bacterial agents. J. Mater. Sci. Mater. Electron. 2018, 29, 13596-13605. [CrossRef]

34. Steffy, K.; Shanthi, G.; Maroky, A.S.; Selvakumar, S. Enhanced antibacterial effects of green synthesized ZnO NPs using Aristolochia indica against Multi-drug resistant bacterial pathogens from Diabetic Foot Ulcer. J. Infect. Public Health 2018, 11, 463-471. [CrossRef] [PubMed]

35. Attar, A.; Yapaoz, M.A. Biomimetic synthesis, characterization and antibacterial efficacy of $\mathrm{ZnO}$ and $\mathrm{Au}$ nanoparticles using echinacea flower extract precursor. Mater. Res. Express 2018, 5, 055403. [CrossRef]

36. Patil, B.N.; Taranath, T. Limonia acidissima L. leaf mediated synthesis of silver and zinc oxide nanoparticles and their antibacterial activities. Microbial Pathog. 2018, 115, 227-232. [CrossRef] [PubMed]

37. Mervat, E.-H.; Ali, H.M.; Ashmawy, N.A.; Salem, M.Z.M. Chemical composition and bioactivity of Salvadora persica extracts against some potato bacterial pathogens. BioResources 2017, 12, 1835-1849.

38. Phattepur, H.; Siddaiah, G.B.; Ganganagappa, N. Synthesis and characterisation of mesoporous $\mathrm{TiO}_{2}$ nanoparticles by novel surfactant assisted sol-gel method for the degradation of organic compounds. Periodica Polytech. Chem. Eng. 2019, 63, 85-95. [CrossRef] 
39. Praveen Kumar, D.; Lakshmana Reddy, N.; Mamatha Kumari, M.; Srinivas, B.; Durga Kumari, V.; Sreedhar, B.; Roddatis, V.; Bondarchuk, O.; Karthik, M.; Neppolian, B.; et al. $\mathrm{Cu}_{2} \mathrm{O}$-sensitized $\mathrm{TiO}_{2}$ nanorods with nanocavities for highly efficient photocatalytic hydrogen production under solar irradiation. Sol. Energy Mater. Sol. Cells 2015, 136, 157-166. [CrossRef]

40. Ezealisiji, K.M.; Siwe-Noundou, X.; Maduelosi, B.; Nwachukwu, N.; Krause, R.W.M. Green synthesis of zinc oxide nanoparticles using Solanum torvum (L.) leaf extract and evaluation of the toxicological profile of the ZnO nanoparticles-hydrogel composite in Wistar albino rats. Int. Nano Lett. 2019, 9, 99-107. [CrossRef]

41. Nagaraju, G.; Nagabhushana, H.; Basavaraj, R.; Raghu, G.; Suresh, D.; Rajanaika, H.; Sharma, S. Green, nonchemical route for the synthesis of $\mathrm{ZnO}$ superstructures, evaluation of its applications toward photocatalysis, photoluminescence, and biosensing. Cryst. Growth Des. 2016, 16, 6828-6840.

42. Leong, K.H.; Aziz, A.A.; Sim, L.C.; Saravanan, P.; Jang, M.; Bahnemann, D. Mechanistic insights into plasmonic photocatalysts in utilizing visible light. Beilstein J. Nanotech. 2018, 9, 628-648. [CrossRef] [PubMed]

43. Suresh, D.; Nethravathi, P.C.; Udayabhanu; Rajanaika, H.; Nagabhushana, H.; Sharma, S.C. Green synthesis of multifunctional zinc oxide ( $\mathrm{ZnO}$ ) nanoparticles using Cassia fistula plant extract and their photodegradative, antioxidant and antibacterial activities. Mater. Sci. Semiconduct. Process. 2015, 31, 446-454. [CrossRef]

44. Udayabhanu.; Nagaraju, G.; Nagabhushana, H.; Suresh, D.; Anupama, C.; Raghu, G.K.; Sharma, S.C. Vitis labruska skin extract assisted green synthesis of $\mathrm{ZnO}$ super structures for multifunctional applications. Ceram. Int. 2017, 43, 11656-11667. [CrossRef]

45. Suresh, D.; Udayabhanu; Nethravathi, P.C.; Lingaraju, K.; Rajanaika, H.; Sharma, S.C.; Nagabhushana, H. EGCG assisted green synthesis of $\mathrm{ZnO}$ nanopowders: Photodegradative, antimicrobial and antioxidant activities. Spectrochim. Acta Part A Mol. Biomol. Spectrosc. 2015, 136, 1467-1474. [CrossRef]

46. Rahman, M.A.; Muneer, M. Photocatalysed degradation of two selected pesticide derivatives, dichlorvos and phosphamidon, in aqueous suspensions of titanium dioxide. Desalination 2005, 181, 161-172. [CrossRef]

47. Chen, S.; Liu, Y. Study on the photocatalytic degradation of glyphosate by $\mathrm{TiO}_{2}$ photocatalyst. Chemosphere 2007, 67, 1010-1017. [CrossRef] [PubMed]

48. Nethravathi, P.C.; Shruthi, G.S.; Suresh, D.; Udayabhanu; Nagabhushana, H.; Sharma, S.C. Garcinia xanthochymus mediated green synthesis of $\mathrm{ZnO}$ nanoparticles: Photoluminescence, photocatalytic and antioxidant activity studies. Ceram. Int. 2015, 41, 8680-8687. [CrossRef]

49. Manjunath, K.; Ravishankar, T.N.; Kumar, D.; Priyanka, K.P.; Varghese, T.; Naika, H.R.; Nagabhushana, H.; Sharma, S.C.; Dupont, J.; Ramakrishnappa, T.; et al. Facile combustion synthesis of ZnO nanoparticles using Cajanus cajan (L.) and its multidisciplinary applications. Mater. Res. Bull. 2014, 57, 325-334. [CrossRef] 